УДК 621.315 .592

\title{
Влияние гамма-облучения на эффект термопереключения монокристалла GeS : Nd
}

\author{
() А.С. Алекперов ${ }^{1}$, А.О. Дашдемиров ${ }^{1}$, Т.Г. Нагиев ${ }^{2}$, С.Г. Джабаров ${ }^{1,2}$ \\ ${ }^{1}$ Азербайджанский государственный педагогический университет, \\ Az-1000 Баку, Азербайджан \\ ${ }^{2}$ Азербайджанский государственный экономический университет (UNEC), \\ Az-1001 Баку, Азербайджан \\ E-mail: sakin@jinr.ru
}

Поступила в Редакцию 17 марта 2021 г.

В окончательной редакции 22 марта 2021 г.

Принята к публикации 22 марта 2021 г.

Исследован эффект термопереключения слоистого монокристалла $\mathrm{GeS}: \mathrm{Nd}$ в широком температурном интервале $(T=80-350 \mathrm{~K})$. Изучено влияние $\gamma$-облучения при разных дозах (30 и 100 крад) на эффект термопереключения монокристалла GeS: Nd. Установлено, что после $\gamma$-облучения в малых дозах, с образованием упорядоченной структуры, в кристалле $\mathrm{GeS}: \mathrm{Nd}$ эффект термопереключения не обнаруживается. С увеличением дозы $\gamma$-облучения до 100 крад происходит деградация структуры, в результате кристалл теряет фоточувствительность, эффект термопереключения не обнаруживается.

Ключевые слова: монокристалл, $\gamma$-облучение, термопереключение, фазовый переход, низкоомное состояние, наноструктура, редкоземельный элемент.

DOI: 10.21883/FTP.2021.07.51011.9649

\section{1. Введение}

Кристаллическая структура и физические свойства полупроводников изучают в течение длительного времени различнымих метододами [1-5]. Среди полупроводниковых материалов слоистые кристаллы обладают уникальными свойствами, так как они используются для записи голограмм, регистрации оптической информации, для создания фотоэлектрических датчиков, электро- и термопереключателей. Повышенный интерес к слоистому монокристаллу моносульфида германия обусловлен возможностями его использования в устройствах электрической памяти [6], для создания солнечных преобразователей [7]. Моносульфид германия является прямозонным материалом, что благоприятствует получению межзонной излучательной рекомбинации и подходит в качестве сырья при производстве солнечных панелей и суперконденсаторов $[8,9]$.

В современной электронике широко используют редкоземельные элементы (РЗЭ) для расширения области применения полупроводниковых кристаллов. Большой ковалентный радиус РЗЭ и образованные ими соединения с другими примесями, в случае попадания их в твердую фазу, приводят к образованию сложных комплексов, атомных кластеров [10].

Проведенные многочисленные исследования, начатые в 80-х годах прошлого столетия, подтверждают, что радиационные излучения в малых дозах $\left(\Phi<10^{6}\right.$ рад) приводят к упорядочению структуры кристаллов [11].

Цель настоящей работы заключается в исследовании влияния $\gamma$-облучения на эффект термопереключения слоистого монокристалла $\mathrm{GeS}: \mathrm{Nd}$.

\section{2. Методика эксперимента}

В качестве исходного материала использовался поликристалл $\mathrm{GeS}: \mathrm{Nd}$, синтезированный методом прямого сплавления. Процесс синтеза осуществлялся в электрической печи марки СУОЛ-1 в два этапа: сначала кварцевая ампула длиной 15-20 см и внутренним диаметром 2.0-2.2 см нагревалась со скоростью $3-5^{\circ} \mathrm{C} /$ мин до $300^{\circ} \mathrm{C}$ и выдерживалась при этой температуре $\sim 20$ ч. На втором этапе температура повышалась до полного плавления неодима $\left(1044^{\circ} \mathrm{C}\right)$, со скоростью $2-3^{\circ} \mathrm{C} / \mathrm{мин}$ и выдерживалась при этой температуре 20 ч. Для получения более однородных поликристаллов ампулу выдерживали при температуре $700^{\circ} \mathrm{C} 72$ ч.

Выращивание слоистых монокристаллов $\mathrm{GeS}: \mathrm{Nd}$ методом сублимации обладает рядом преимуществ по сравнению с методом Бриджмена. Халькогениды германия обладают достаточно высоким давлением паров, благодаря чему массоперенос через газовую фазу осуществляется легко. Кристаллизация из газовой фазы совершается при низких температурах. В результате концентрация вакансий и дефектов сводится к минимумy [12,13].

Принцип статического метода роста сводится к следующему. Рост кристаллов происходит в горизонтальных двухзонных печах. В начальный момент обе зоны печи имели одинаковую температуру (на $30^{\circ} \mathrm{C}$ ниже $T_{\text {melt }}=607^{\circ} \mathrm{C}$ ). При уменьшении температуры в одной из зон печи, где находится ампула длиной 15-20 см и диаметром 2.0-2.2 см, давление в ампуле практически не изменяется. С понижением температуры увеличивается пересыщение пара и возникают зародыши кристал- 
лов. С ростом этих зародышей вырастали пластинчатые кристаллы размерами $12 \times 10 \times 0.2$ мм, с осью $c$, перпендикулярной плоскости спайности.

Для измерения температурной зависимости электропроводности слоистых монокристаллов $\mathrm{GeS}: \mathrm{Nd}$, в температурном интервале $T=80-350 \mathrm{~K}$, был использован азотный криостат. Температура образца измерялась платиновым датчиком марки ИС-568А, сопротивление которого изменяется в соответствии с линейным законом в данном температурном интервале. Малая инерционность криостата обеспечивала быстрый нагрев кристаллов. Специальная система термостатирования позволила контролировать изменение температуры в данном диапазоне. Омические контакты наносились аквадаком. Электропроводность, в том числе сопротивление образца, измерялись тераомметром марки Е6-13. Для того чтобы ток в образце не превысил максимального значения, в электрическую цепь был включен ограничительный резистор. Температурная зависимость электропроводности кристаллов проводилась в темноте, при разном освещении белым светом, до и после $\gamma$-облучения.

Кристаллическая структура и фазовый состав материалов исследовались методом дифракции рентгеновских лучей с использованием дифрактометра D8 ADVANCE на излучении $\mathrm{CuK}_{\alpha}(\lambda=1.5418 \AA)$.

Облучение образцов $\gamma$-квантами проводили при комнатной температуре на установке РХУНД-20000 от источника ${ }^{60} \mathrm{Co}$ с мощностью фазы в зоне облучения $\sim 1.37 \mathrm{P} / \mathrm{c}$.

\section{3. Экспериментальные результаты}

Была исследована температурная зависимость электропроводности слоистого монокристалла $\mathrm{GeS}: \mathrm{Nd}$ в темноте, при освещении до и после $\gamma$-облучения дозой 30 крад.

Как видно из рис. 1, с увеличением температуры величина тока, через образцы на начальном участке, растет по линейному закону, затем по степенному с показателем 2-4 и далее при определенной температуре увеличивается скачком. В низкоомном состоянии электропроводность носит металлический характер и кристалл теряет фоточувствительность. Температура скачкообразного перехода зависит от освещенности монокристалла, а с увеличением освещения температура перехода в низкоомное состояние уменьшается. Наблюдаемый нами эффект термопереключения носит запоминающийся характер, число переключений очень большое. Как в фоточувствительном, так и низкоомном состоянии образец находился длительное время. С уменьшением температуры монокристалл $\mathrm{GeS}: \mathrm{Nd}$ восстанавливает исходное - фоточувствительное состояние.

Следует отметить, что при идентичных условиях, в образцах $\mathrm{GeS}: \mathrm{Nd}$ после $\gamma$-облучения малой дозой (30 крад) эффект термопереключения не наблюдается. С увеличением дозы $\gamma$-облучения до 100 крад происходит деградация структуры, в результате кристалл теряет

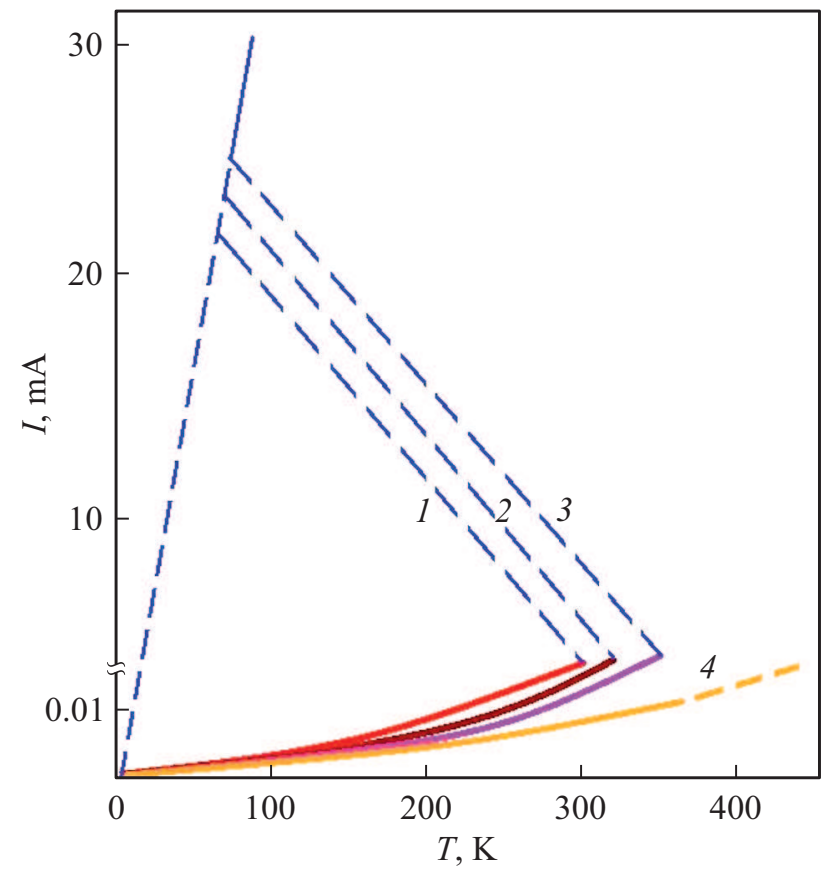

Рис. 1. Температурная зависимость электропроводности слоистого монокристалла GeS: Nd. До облучения, Ф, лм: $1-250$, $2-500,3-1000$, после облучения дозой 30 крад: $4-\Phi=1000$ лм.

фоточувствительность, эффект термопереключения не обнаруживается.

\section{4. Обсуждение результатов}

В настоящее время существуют две точки зрения на природу эффекта переключения в слоистых кристаллах [14]. Согласно одной из них, эффект переключения связан с обратимым электронно-тепловым пробоем. По другой точке зрения, природа эффекта переключения чисто электронная. Еще в 60-х годах прошлого века Коломиец с соавт. [15] показали, что тепловая теория достаточно хорошо описывает эффект переключения в пленках толщиной > 10 мкм и в слоистых кристаллах. Поэтому причиной эффекта переключения в слоистом монокристалле $\mathrm{GeS}: \mathrm{Nd}$ с толщиной 200 мкм является обратимый тепловой пробой.

Как видно из рис. 2, $a, b$, при идентичных условиях температура пробоя для монокристалла $\mathrm{GeS}: \mathrm{Nd}$ больше, чем для монокристалла GeS. После $\gamma$-облучения малой дозой (30 крад) эффект термопереключения для кристаллов $\mathrm{GeS}: \mathrm{Nd}$ не обнаруживается.

При легировании соединения $\mathrm{GeS}$ примесью $\mathrm{Nd}$ возникают дополнительные дефекты. Из-за существенно большого различия размеров атома вводимой примеси $\left(r_{\mathrm{Nd}}=0.96 \AA\right)$ и замещаемого атома $\left(r_{\mathrm{Ge}}=0.72 \AA\right)$ процесс легирования сопровождается генерированием дополнительных собственных точечных дефектов. В области малых концентраций атомы Nd преимущественно растворяются в вакансиях. При наличии свободных 
вакансий возможно также растворение примеси $\mathrm{Nd}$ в значительных количествах путем замещения германия в узлах решетки. С учетом этих данных можно предположить, что механизм растворения малых концентраций примеси $\mathrm{Nd}$ в моносульфиде германия приводит к „залечиванию“ катионных вакансий. В результате сопротивление моно-кристалла $\mathrm{GeS}$ возрастает на 2 порядка. С увеличением удельного сопротивления возрастает и величина напряжения переключения.

В начале 80-х годов прошлого столетия считалось, что облучение кристаллов, металлов и сплавов заряженными частицами и $\gamma$-квантами приводит к нарушению их структуры [16,17]. Существовала общепринятая точка зрения, согласно которой при облучении потоками частиц, меньшими на несколько порядков величины концентраций носителей заряда в полупроводниковых кристаллах, никаких изменений физических свойств не происходит $[18,19]$. Однако в результате экспериментальных исследований было установлено [20], что процесс взаимодействия ионизирующего излучения с кристаллами не соответствует общепринятым представлениям в том случае, когда поглощенная доза составляет $\sim 10^{5}$ Гр. Оказалось, что облучение $\gamma$-квантами указанной поглощенной дозой ионизирующего излучения полупроводниковых кристаллов приводит не к накоплению дефектов, а наоборот, к их устранению и упорядочению структуры материалов [21].

Перестройка структуры кристалла при облучении малыми дозами $\gamma$-квантов происходит за счет освобождения накопленной в кристалле энергии. Уменьшение количества дефектов в кристалле в процессе облучения сопровождается тепло-выделением, обусловленным аннигиляцией и перестройкой дефектов [22,23].

В кристалле $\mathrm{GeS}$ под действием $\gamma$-квантов разрушаются дислокационные петли, которые образовались при объединении мелких ассоциаций точечных дефектов, снижается концентрация дефектов и микронапряжений в кристалле. Упорядочение структуры под действием $\gamma$-квантов происходит очень слабо и интенсивность рефлексов возрастает всего в 2.25 раза.

Эффект упорядочения структуры в более ярком виде был обнаружен в кристалле $\mathrm{GeS}: \mathrm{Nd}$. После облучения малой дозой (30 крад) монокристалла $\mathrm{GeS}: \mathrm{Nd}$ резко (в $\sim 30$ раз) возрастает интенсивность рефлексов сверхструктурного максимума (рис. $2, a, b)$.

Качественно картину процессов, происходящих в монокристалле GeS: Nd при воздействии малых доз $\gamma$-излучения (30 крад), можно объяснить следующим образом.

$\gamma$-кванты создают в кристалле электронно-дырочные пары. Эти пары в полупроводниковых кристаллах существуют достаточно длительное время. Мигрируя по кристаллу, они захватываются дефектами, образуя заряженные межузельные атомы и вакансии или их скопления. Заряженные дефекты интенсивно взаимодействуют между собой. Одноименные дефекты сливаются и образуют более крупные комплексы межузельных атомов или вакансий. В случае встречи разноименных дефектов
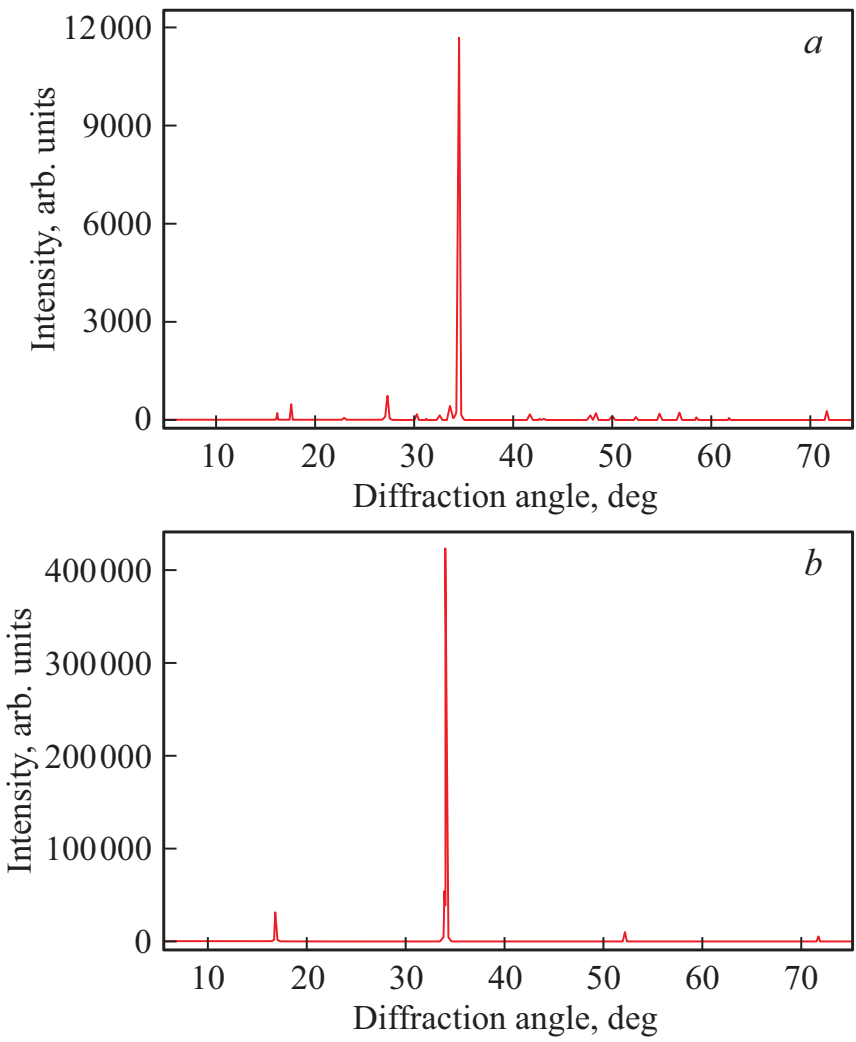

Рис. 2. Рентгенографические дифрактограммы монокристалла $\mathrm{GeS}: \mathrm{Nd}: a-$ до облучения, $b-$ после облучения дозой 30 крад.

происходит их аннигиляция. При аннигиляции электрона и дырки генерируется фотон.

Фотон способен взаимодействовать с комплексами (в состав которых входят РЗЭ и кислород) и разваливать их. Освободившийся кислород покидает кристалл, а появившиеся свободные межузельные атомы аннигилируют с вакансиями. При аннигиляции пар Френкеля выделяется энергия, и за счет этой энергии возникают новые электронно-дырочные пары. Последние снова захватываются дефектами, которые аннигилируют. Описанный процесс изменяет состояние кристалла и приводит к упорядочению структуры кристалла. В таком случае под действием температуры эффект переключения не осуществляется.

\section{5. Заключение}

Исследования температурных зависимостей электропроводности слоистых монокристаллов $\mathrm{GeS}$ и $\mathrm{GeS}: \mathrm{Nd}$ показывают, что примесные атомы $\mathrm{Nd}$, компенсируя катионные вакансии, значительно (в $\sim 10^{2}$ раз) увеличивают удельное сопротивление монокристалла $\mathrm{GeS}$, благодаря чему увеличивается и значение напряжения переключения.

$\gamma$-облучение в малых дозах приводит к упорядочению структуры кристалла. „Залечивание“ редкоземель- 
ных элементов, в том числе атомов $\mathrm{Nd}$, способствует усилению этого процесса. В результате в кристалле $\mathrm{GeS}: \mathrm{Nd}$ формируется „идеальная“ структура и эффект термопереключения в данном температурном интервале не обнаруживается. При увеличении $\gamma$-облучения до 100 крад идет деградация структуры, образец теряет фоточувствительность.

\section{Конфликт интересов}

Авторы заявляют, что у них нет конфликта интересов.

\section{Список литературы}

[1] M.S. Leanenia, E.V. Lutsenko, M.V. Rzheutski, G.P. Yablonskii, T.G. Naghiyev, H.B. Ganbarova, O.B. Tagiev. Optical Mater., 54, 45 (2016).

[2] Y.I. Aliyev, Y.G. Asadov, T.M. Ilyasli, F.M. Mammadov, T.G. Naghiyev, Z.A. Ismayilova, M.N. Mirzayev, S.H. Jabarov. Mod. Phys. Lett. B, 34, 2050066 (2020).

[3] G.S. Orudjev, N.A. Ismayilova. Adv. Phys. Res., 1, 37 (2019).

[4] Y.I. Aliyev, Y.G. Asadov, A.O. Dashdemirov, R.D. Aliyeva, T.G. Naghiyev, S.H. Jabarov. Inter. J. Mod. Phys. B, 33, 1950271 (2019).

[5] S.G. Asadullayeva, T.G. Naghiyev, G.A. Gafarova. Adv. Phys. Res., 1, 81 (2019).

[6] Д.И. Блецкан, В.И. Таран, М.Ю. Сичка. УФЖ, 9, 1436 (1976).

[7] Д.И. Блецкан, В.Н. Кабацкий, М.М. Блецкан. Современные инбормационные и электронные технологии (Одесса, 2015) с. 228.

[8] J. Lui, X.W. Liu. Adv. Mater., 24, 4097 (2012).

[9] Li. Chun, H. Jiang, P.S. Gayatri, Yu. Yifei, C. Linyou. ACS Nano, 9, 8868 (2012).

[10] М.Г. Мильвидский, В.В. Чалдышев. ФТП, 17, 513 (1998).

[11] И.П. Чернов, А.П. Мамонтов. Изв. Томского политехнического университета (Томск, 1994) с. 74.

[12] Д.И. Блецкан, И.Ф. Копинец, П.П. Погорецкий, Е.Н. Салькова, Д.В. Чепур. Кристаллография, 20, 1008 (1975).

[13] Д.И. Блецкан. УФЖ, 24, 321 (1979).

[14] Н.А. Богословский, К.Д. Цэндин. ФТП, 46, 577 (2012).

[15] Б.Т. Коломиец, Э.А. Лебедев, И.А. Таксами. ФТП, 3, 312 (1969).

[16] В.Т. Мак. Письма ЖТФ, 15, 17 (1989).

[17] В.Т. Мак. ЖТФ, 63, 173 (1993).

[18] А.С. Белоус, В.А. Солодуха, С.В. Шведов. Высокоскоростные электронные устройства (М., Техносфера, 2017).

[19] K. Cenzual, L. Louise, M. Gelato, M. Penzo, E. Parthe. Acta Cryst., 47, 433 (1991).

[20] А.П. Мамонтов, И.П. Чернов. Эфббект малых доз ионизирующего излучения (Томск, Дельтаплан, 2009).

[21] И.П. Чернов, А.П. Мамонтов, А.А. Ботаки. Атом. энергия, 57, 56 (1984).

[22] И.П. Чернов, А.П. Мамонтов, П.А. Черданцев. Изв. вузов. Физика, 12, 58 (1994).

[23] D.W. Zhang, F.T. Jin, J.M. Yuan. Chin. Phys. Lett., 23, 1876 (2006).

\section{Gamma irradiation effect on thermal switching of GeS: Nd single cristal}

\author{
A.S. Alekperov ${ }^{1}$, A.O. Dashdemirov ${ }^{1}$, T.G. Naghiyev ${ }^{2}$, \\ S.H. Jabarov ${ }^{1,2}$ \\ ${ }^{1}$ Azerbaijan State Pedagogical University, \\ Az-1000 Baku, Azerbaijan \\ ${ }^{2}$ Azerbaijan State University of Economics, \\ Az-1001 Baku, Azerbaijan
}

\begin{abstract}
The effect of thermal switching of layered GeS:Nd single crystal is investigated in a wide range of temperature $(T=80-350 \mathrm{~K})$. Gamma irradiation effect at different doses (30 krad and $100 \mathrm{krad}$ ) on thermal switching of $\mathrm{GeS}: \mathrm{Nd}$ single crystal was studied. It was found that the effect of thermal switching is not observed in the GeS: $\mathrm{Nd}$ crystal after gamma irradiation in low doses, with the formation of an ordered structure. The degradation is observed in the structure when gamma irradiation increased to $100 \mathrm{krad}$, resulting in the crystal loses its photosensitivity and thermal switching effect is not detected.
\end{abstract}

